\title{
What can we learn from the SARS-COV-2 pandemic about the value of specific radiological examinations?
}

\author{
Bjørn Hofmann ${ }^{1,2^{*}}$, Eivind Richter Andersen ${ }^{1}$ and Elin Kjelle ${ }^{1}$
}

\begin{abstract}
Background: The SARS-COV-2 pandemic provides a natural intervention to assess practical priority setting and internal evaluation of specific health services, such as radiological services. Norway makes an excellent case as it had a very low infection rate and very few cases of COVID-19. Accordingly, the objective of this study is to use the changes in performed outpatient radiological examinations during the first stages of the SARS-COV-2 pandemic to assess the practical evaluation of specific radiological examinations in Norway.

Methods: Data was collected retrospectively from the Norwegian Health Economics Administration (HELFO) in the years 2015-2020. Data included the number of performed outpatient imaging examinations at public hospitals and private imaging centers in Norway and was divided in to three periods based on the level of restrictions on elective health services. Results were analyzed with descriptive statistics.

Results: In the first period there was a $45 \%$ reduction in outpatient radiology compared to the same time period in 2015-2019 while in period 2 and 3 there was a 25 and 6\% reduction respectively. The study identified a list of specific potential low-value radiological examinations. While some of these are covered by the Choosing Wisely campaign, others are not.

Conclusion: By studying the priority setting practice during the initial phases of the pandemic this study identifies a set of potential low value radiological examinations during the initial phases of the SARS-COV-2 pandemic. These examinations are candidates for closer assessments for health services quality improvement.
\end{abstract}

Keywords: Low-value care, Appropriateness, Choosing wisely, Ethics, Covid-19, SARS-COV-2

\section{Key points}

- The SARS-COV-2 pandemic has reduced the outpatient radiological examinations with 45,25 and $6 \%$ during the three initial phases of the pandemic.

- The pandemic provides a natural intervention to study the value of specific radiological examinations.

\footnotetext{
* Correspondence: bjoern.hofmann@ntnu.no

1 Institute for the Health Sciences at the Norwegian University of Science and Technology (NTNU) at Gjøvik, PO Box 191, N-2802 Gjøvik, Norway

${ }^{2}$ Centre of Medical Ethics at the University of Oslo, Oslo, Norway
}

- A set of specific examinations are identified as candidates for health services quality improvement.

\section{Introduction}

During the first period of the SARS-COV-2 pandemic in Norway (March-June 2020), activities at Norwegian hospitals were reduced to a minimum, including postponing outpatient services, elective surgery, and scheduled follow ups. However, the number of persons affected by the pandemic was very small compared to other countries. Figure 1 shows some key figures for the first

C C The Author(s). 2021 Open Access This article is licensed under a Creative Commons Attribution 4.0 International License, which permits use, sharing, adaptation, distribution and reproduction in any medium or format, as long as you give appropriate credit to the original author(s) and the source, provide a link to the Creative Commons licence, and indicate if changes were made. The images or other third party material in this article are included in the article's Creative Commons licence, unless indicated otherwise in a credit line to the material. If material is not included in the article's Creative Commons licence and your intended use is not permitted by statutory regulation or exceeds the permitted use, you will need to obtain permission directly from the copyright holder. To view a copy of this licence, visit http://creativecommons.org/licenses/by/4.0/ The Creative Commons Public Domain Dedication waiver (http://creativecommons.org/publicdomain/zero/1.0/) applies to the data made available in this article, unless otherwise stated in a credit line to the data. 




Fig. 1 The number of tested (positive), infected, hospitalized, persons in the ICU, and deaths during the first months of the outbreak in Norway from March 1 to June 30. Data are available at the Norwegian Institute of Public health (www.fhi.no)

months of the outbreak in Norway. By June 30 there were 251 covid-19 related deaths in Norway.

While very few health services were directly involved in handling covid-19 patients, all were significantly affected as elective activities were initially reduced to a minimum and then gradually opened again. The event provides a natural intervention to study health services practical priority setting and an unprecedented opportunity to assess practical evaluation of specific health services $[1,2]$.

One specific area for investigation is radiological services. Radiological technologies provide tremendous opportunities for diagnostics and subsequent treatment and care. This has significantly expanded the possibilities to help people [3], but also the potential for unnecessary, inappropriate, futile, or even harmful examinations [4-6]. Furthermore, critical reflections have emerged on whether there is "too much medicine" [7-12] and too much radiology $[4,13-16]$.

Internationally a wide range of campaigns, such as Choosing Wisely, Too Much Medicine (BMJ), Smarter Medicine, Prudent Health Care, Slow Medicine, Do Not Do (NICE) [17], have focused on (in)appropriate and low value care, defined as "an intervention in which evidence suggest it confers not or very little benefit for patients, or risk of harm exceeds probable benefit or, more broadly, the added costs of the intervention do not provide proportional added benefits" [18]. Accordingly, a negative test can have positive value and a positive test can have low value. While there are many consensusbased suggestions for low-value radiological services [5, 19-22] the extension of low value radiology is still unclear, as examinations identified as "low-value" can be of great value in specific cases [23]. Hence, it can be difficult to define and identify low-value care in radiological practice. This is especially important in perspective of value-based radiology [24-26].

However, the pandemic provides a unique opportunity to investigate what happens to health services when forced to prioritize in a strict manner. From an ethical perspective, one should always try to learn as much as possible when crisis occurs.

Thus, the purpose of this study was to assess changes in performed outpatient radiological examinations during the first stages of the SARS-COV-2 pandemic and apply this to study the practical evaluation of radiological examinations. In order to improve health services, we focus on examinations that potentially are of low value.

To address this overall issue the specific research questions are:

- Which examinations were reduced most during the pandemic?

- What are the patterns of reduced radiological services during the SARS-COV-2 pandemic in 2020?

- How well does the reduction in services correspond to the recommendations of the Choosing Wisely Campaign in Norway and the USA?

\section{Material and methods}

The data for this study was all outpatient radiological examinations registered at the Norwegian Health 
Economics Administration (HELFO) for three specific periods in the years 2015-2020. The periods were defined by the reactions of the Norwegian health authorities and the Government to the SARS-COV-2 pandemic in 2020:

Period 1 is from March 12 till April 11, "the shutdown period", during which only extraordinarily important and severe cases were examined. Several outpatient services were shut down and elective surgery was postponed.

Period 2 from April 12 till May 12, a slight let up in restrictions and important cases were examined in addition to increased outpatient activity in general.

Period 3 is from May 13 till June 12, further let up in restrictions and the radiology departments returned to almost normal outpatient activities.

Results were analyzed with descriptive statistics in Microsoft Excel for Office 365 ProPlus.

Data were grouped and subsumed under main codes (2020) including additional codes from the Norwegian Classification of Radiological Procedures (NCRP) [27]. Codes from 2015 were transposed to 2020 version of codes, as there was a major shift in nomenclature from 2015 to 2016 . The average and relative standard deviation was calculated for each code for each period and compared to the subsumed number of examinations for the corresponding month in 2020 .
Changes less than $50 \%$ for specific examinations in Period 1 were excluded as these examinations were considered to be of high value. Figure 2 illustrates the model applied in this study. In order to avoid artifacts due to small numbers, averages of less than 100 examinations per months were excluded. Reduction in the number of examinations was calculated as the difference in a given period (Period 1-3) in 2020 from the stable average for the same period for the years 2015-2019 in percent.

\section{Results}

There were about 256,000 examinations for all three periods between 2015 and 2019 and the relative standard deviation varied between 4 and $12 \%$, as can be seen in Table 1. The reduction for each period from 2015 to 2019 to 2020 varies from $45.5 \%$ in Period 1 to $6.1 \%$ in Period 3.

Table 2 shows the reduction in number of examinations for the four main radiological modalities from 2019 to 2020 for each of the three periods. While the number of examinations were reduced for all modalities during the first period, the lowest relative reduction was in ultrasound. The use of ultrasound increased during the second period and then decreased again while CT increased in the last period compared to 2019.

For the main examinations in adults identified by the Norwegian version of the Choosing Wisely Campaign [28], the development of the number of examinations are shown in Fig. 3.

As the figure illustrates, most of the identified examinations were reduced from one to two third of the normal level but increasing in period 2 and 3.

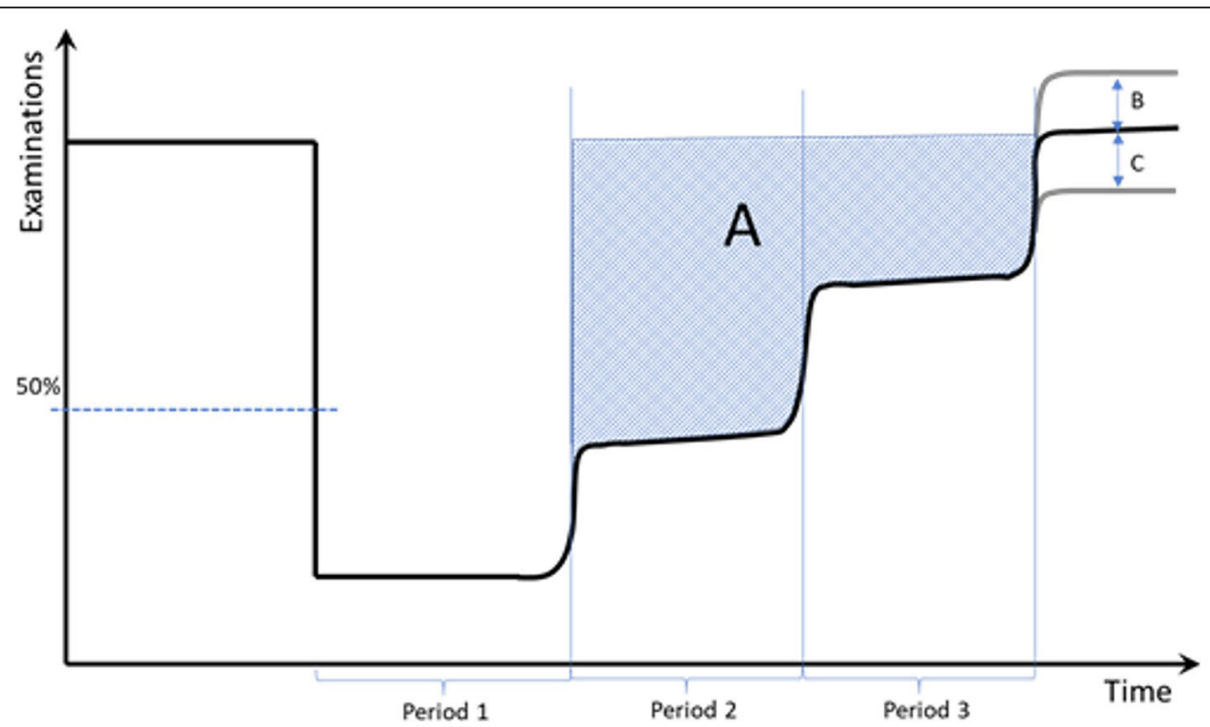

Fig. 2 Model used for measuring reduced examinations during the various periods of the pandemic. A refers to the total volume of examinations reduced during the phases when the radiological departments were opening up. B indicates an increased activity post opening and may indicate a backlog while $\mathrm{C}$ indicates a long-lasting reduction 
Table 1 Average outpatient main examinations for three periods in 2015-2019 compared to the same periods in 2020

\begin{tabular}{llllll}
\hline & $\begin{array}{l}\text { Average } \\
\text { 2015-2019 }\end{array}$ & SD & \%RSD & 2020 & Overall reduction (\%) \\
\hline Period 1 & 254,424 & 29,391 & 11.6 & 140,328 & 45.5 \\
Period 2 & 256,695 & 24,859 & 9.7 & 194,375 & 25.4 \\
Period 3 & 259,724 & 10,281 & 4 & 247,366 & 6.1 \\
\hline
\end{tabular}

While the use of most examinations followed the pattern in Table 1 and Fig. 2, i.e., with a stable number of examinations for all three periods (2015-2019), and a substantial reduction in the first period and then a gradual increase in the subsequent periods in 2020, some examinations had a significant reduction in period 1 however increased beyond the previous average in period 3. One example of this is bone density measurement (DEXA), illustrated in Fig. 4.

Further, some types of examinations were substantially reduced during all three periods as shown in Fig. 5.

Other examinations had a larger reduction during Period 1, however still regained activity during Period 2 and 3. Examples of this are typical conventional $\mathrm{x}$-ray examinations of the hip, knee, foot and hand, as shown in Fig. 6, which reveals a small expected seasonal increase for these examinations.

Table 3 shows the examinations that had a large reduction $(>20 \%)$ in period 2 and durable reduction $(>$ $10 \%$ ) on average for period 2 and 3. The number of examinations is given to indicate the volume. As the table demonstrates, a series of examination have more than $50 \%$ reduction even in period 2 and 3: KUB view, CT Enterography, MRI Pelvis and lower limb, Throat and neck ultrasound, MRI Thoracic spine, MRI sacroiliac joints, Liver, gall bladder, and pancreatic ultrasound, Axillary ultrasound and MRI of the face. CT was the modality with the lowest number of examination codes to have a large reduction in use, while ultrasound and conventional radiography had the largest amount of examination codes with a large reduction in use. Among the defined low value examinations in the Choosing Wisely campaign, imaging of the spine [28] and ultrasound of the throat and neck [5] had the largest reduction.

\section{Discussion}

This study shows a substantial reduction of the number of outpatient examinations during the initial phases of the SARS-COV-2 pandemic in 2020 and concur with other studies [29-34]. As a natural intervention it can teach us about practical priority setting, i.e., how specific radiological examinations are valued in practice. As such, it can help us identify potential low value radiological services.

Clearly, low value care cannot be read out of the data directly. Careful scrutiny of examination codes and indications is necessary. Moreover, we must assess whether there are unintended consequences associated with the abrupt reduction in imaging, e.g., delayed diagnoses and treatments, and excess mortality. For example, it has been documented that the number of treated injuries was reduced during the first weeks of the pandemic [35], that the reduction in imaging exacerbated inequities [36], had economic consequences [37], and influenced radiology trainees [38]. However, it is too early to assess the implications of the reduction in imaging on people's health. It is also important to notice that health services in general were mostly reduced for milder illnesses [39]. Hence, the study is an important step in identifying lowvalue care and to improve the health services. The approach demonstrates how we can learn from the pandemic and it supplements other ways to identify low value care. The approach is also recognized and applied in many other fields [39-48] to identify and reduce a range of low-value services.

The reduction in the first period cannot be used to assess the value of radiological services as it certainly included reduction of high value services. However, reduction of examinations during the second and third period, can teach us about priority setting in practice. Accordingly, the following examinations are candidates for being of low value and merit further investigation: Abdominal KUB view, CT Enterography, MRI Pelvis and lower limb, Throat and neck ultrasound, MRI Thoracic spine, MRI sacroiliac joints, Liver, gall bladder and pancreatic ultrasound, Axillary ultrasound and MRI of the face. Of these, Throat and neck ultrasound, MRI of Thoracic spine, sacroiliac joints and face are the ones related to Choosing Wisely recommendations [5].

Table 2 Reduced examinations for different modalities in all three periods comparing 2019 and 2020 in numbers and percentages. Negative reduction means increase

\begin{tabular}{|c|c|c|c|c|c|c|}
\hline \multirow[t]{2}{*}{ Examination } & \multicolumn{2}{|l|}{ Period 1} & \multicolumn{2}{|l|}{ Period 2} & \multicolumn{2}{|l|}{ Period 3} \\
\hline & Reduction (n) & Reduction (\%) & Reduction (n) & Reduction (\%) & Reduction (n) & Reduction (\%) \\
\hline$\overline{\mathrm{CT}}$ & 33,803 & 57.57 & 15,600 & 33.48 & $-12,374$ & -20.87 \\
\hline Conventional radiography & 59,094 & 57.52 & 8474 & 12.84 & 8943 & 11.56 \\
\hline MRI & 48,833 & 56.17 & 9142 & 15.27 & 12,338 & 16.35 \\
\hline Ultrasound & 16,614 & 36.11 & $-11,444$ & -28.8 & 9516 & 17.2 \\
\hline
\end{tabular}




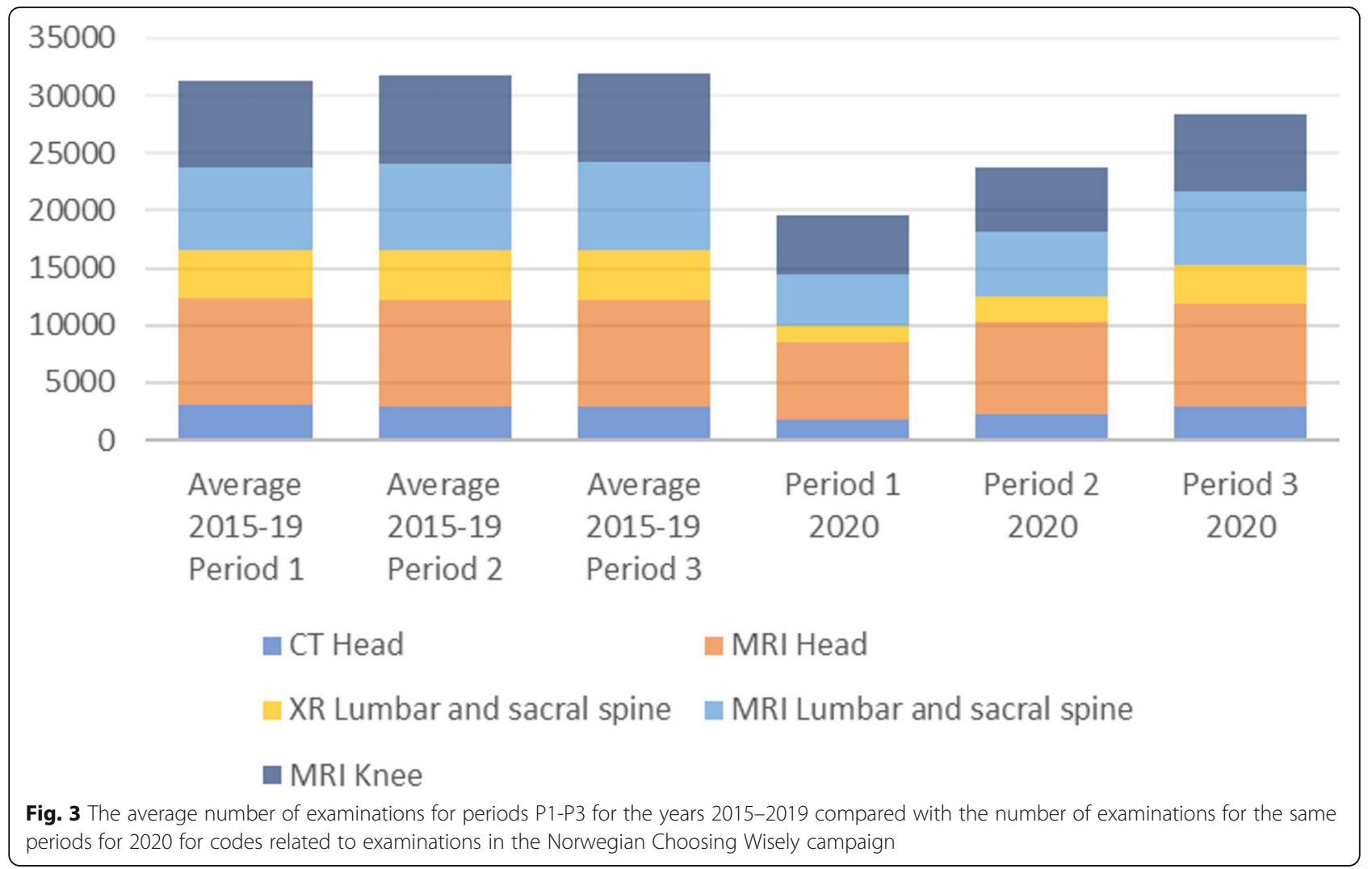

Our study provides useful insights of the practical priority setting of radiological services. Interestingly, we found that utilization of bone density examinations (DEXA), increased in the third period after the lockdown. This can be the result of a backlog, but also because this service is provided by special departments with few other services and high capacity. However, frequent DEXA screening for osteoporosis in elderly is in

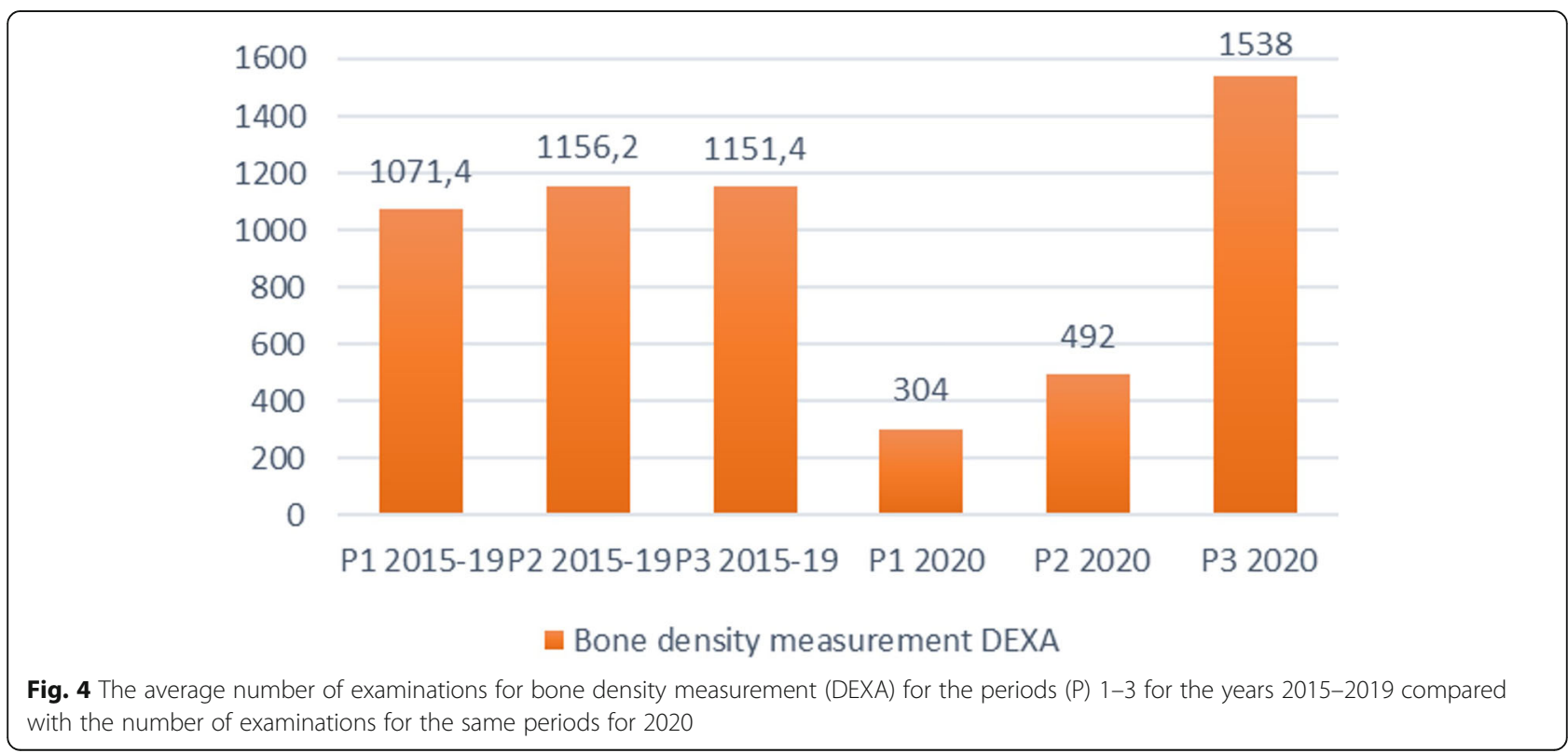




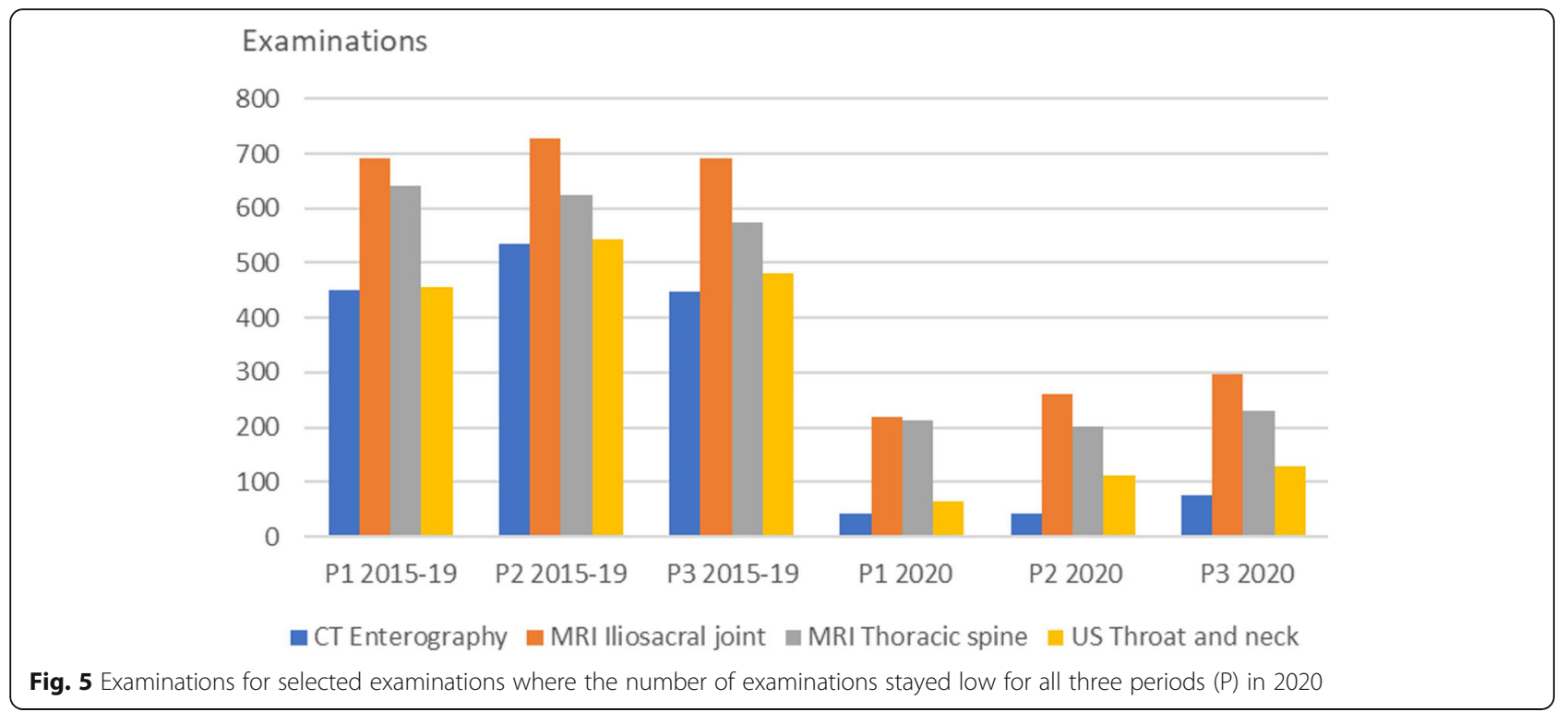

the literature considered as low value care [49]. This underscores our point that the identified examinations need further scrutiny.

Only five CT-examinations were reduced more than $20 \%$ in period 2 (Table 3), despite a $57 \%$ reduction in the first period. The high utilization of CT during the pandemic may be due to prioritizing cancer pathways and cancer follow up, which was prioritized in the Norwegian health services during the lock down [50]. This could indicate that most CT-examinations are of high value or that it is difficult to reduce the use of CT examinations in Norwegian hospitals. This merits further scrutiny since CT represents high volume and high radiation doses [51].
One of our aims was to investigate how well the reduction in services corresponds to the recommendations of the Norwegian Choosing Wisely Campaign [28]. Our findings suggest that the practical priority setting only partly corresponded to the campaign. Most examinations were initially reduced from one to two third of the normal level but increased again in period 2 and 3. This could indicate that recommendations from the Norwegian Choosing Wisely Campaign were not followed when opening in period 3. However, the Norwegian version of the campaign include only six specific examinations and indications. Our findings suggest that several radiological examinations have potential to be low value. This corresponds to international literature where more

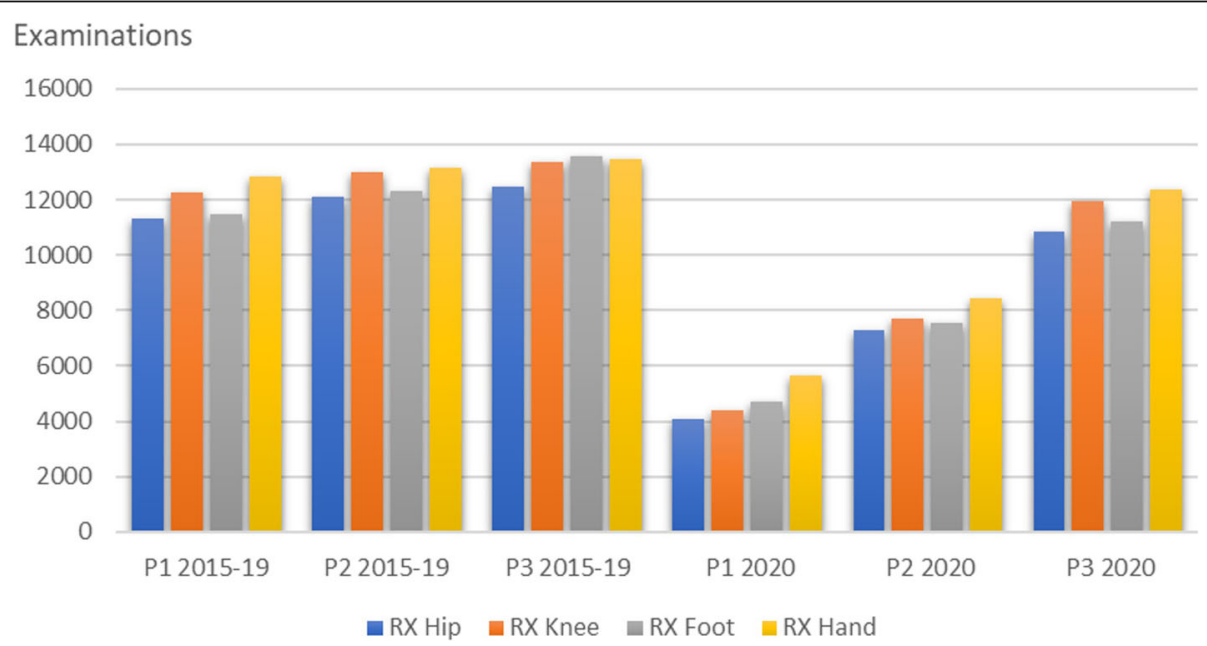

Fig. 6 Examples of examinations where the initial reduction was reduced from Period $(P) 1$ to Period 3 
Table 3 Average reduction (in \%) for period (P) 2 and 3 for examinations with more than 20\% reduction for period 2 including the average number of examinations for each period 2015-2019 as well as for 2020

\begin{tabular}{|c|c|c|c|c|c|c|c|}
\hline Examination & $\begin{array}{l}\text { Average reduction in } \\
\text { P2 and P3 (\%) }\end{array}$ & $\begin{array}{l}\text { Exam. in P1 } \\
2015-2019\end{array}$ & $\begin{array}{l}\text { Exam. in P2 } \\
2015-2019\end{array}$ & $\begin{array}{l}\text { Exam. in P3 } \\
2015-2019\end{array}$ & $\begin{array}{l}\text { Exam. } \\
\text { in } \mathrm{P} 1 \\
2020\end{array}$ & $\begin{array}{l}\text { Exam. } \\
\text { in P2 } \\
2020\end{array}$ & $\begin{array}{l}\text { Exam. } \\
\text { In P3 } \\
2020\end{array}$ \\
\hline \multicolumn{8}{|l|}{ Conventional Radiography } \\
\hline KUB (Kidney, ureters and bladder) & 86.8 & 107 & 98 & 101 & 20 & 12 & 11 \\
\hline Orthopantomography & 47.5 & 168 & 174 & 167 & 10 & 78 & 80 \\
\hline Sacroiliac joints ${ }^{a b}$ & 47.2 & 299 & 310 & 326 & 74 & 112 & 184 \\
\hline Cervical spine & 43.2 & 1417 & 1407 & 1319 & 466 & 610 & 816 \\
\hline Sacrum and coccyx & 36.8 & 297 & 275 & 234 & 74 & 138 & 172 \\
\hline Chest $^{\mathrm{b}}$ & 30.4 & 23,868 & 23,265 & 22,715 & 9557 & 13,215 & 16,856 \\
\hline Thoracic, lumbar, and sacral spine ${ }^{b}$ & 27.9 & 549 & 532 & 544 & 185 & 256 & 468 \\
\hline Abdominal & 27.5 & 754 & 738 & 761 & 330 & 418 & 597 \\
\hline Lumbar and sacral spine $e^{\mathrm{ab}}$ & 26.8 & 4180 & 4244 & 4281 & 1382 & 2307 & 3440 \\
\hline Thoracic and lumbar spine ${ }^{b}$ & 26.5 & 232 & 271 & 233 & 76 & 151 & 183 \\
\hline Thoracic spine ${ }^{b}$ & 25.9 & 1184 & 1166 & 1111 & 446 & 684 & 909 \\
\hline Ribs & 22.4 & 297 & 285 & 265 & 124 & 185 & 226 \\
\hline Shoulder & 22.2 & 6901 & 6452 & 6118 & 2890 & 4140 & 5340 \\
\hline Calf & 19.6 & 2312 & 2261 & 2157 & 1092 & 1532 & 1877 \\
\hline Foot $^{b}$ & 19.6 & 11,463 & 12,315 & 13,551 & 4695 & 7565 & 11,211 \\
\hline Hip & 19.0 & 11,291 & 12,101 & 12,462 & 4085 & 7300 & 10,825 \\
\hline Knee & 18.4 & 12,262 & 13,002 & 13,347 & 4402 & 7721 & 11,967 \\
\hline Total spine & 16.5 & 714 & 733 & 737 & 203 & 494 & 644 \\
\hline Hand & 16.3 & 12,825 & 13,138 & 13,448 & 5638 & 8437 & 12,360 \\
\hline Ankle ${ }^{b}$ & 13.8 & 8765 & 9262 & 9520 & 4226 & 6470 & 8573 \\
\hline Upper arm & 13.3 & 964 & 892 & 859 & 569 & 676 & 832 \\
\hline Pelvis & 13.2 & 8626 & 8954 & 9164 & 3348 & 5960 & 8677 \\
\hline Wrist & 12.7 & 9424 & 8903 & 9203 & 4892 & 6405 & 8902 \\
\hline Clavicle & 12.1 & 1352 & 1295 & 1395 & 642 & 983 & 1274 \\
\hline Femur & 11.7 & 814 & 796 & 791 & 376 & 599 & 747 \\
\hline \multicolumn{8}{|l|}{ Computed tomography } \\
\hline Enterography & 85.4 & 451 & 535 & 448 & 42 & 42 & 77 \\
\hline Colonography with fecal tagging & 19.5 & 437 & 488 & 496 & 295 & 359 & 412 \\
\hline Face ${ }^{b}$ & 17.6 & 473 & 477 & 488 & 230 & 326 & 422 \\
\hline Sinuses ${ }^{b}$ & 15.5 & 2670 & 2542 & 2358 & 1392 & 1878 & 2187 \\
\hline Lumbar and sacral spine ${ }^{a b}$ & 13.8 & 416 & 432 & 435 & 204 & 311 & 390 \\
\hline \multicolumn{8}{|l|}{ Magnetic resonance imaging } \\
\hline Pelvis and lower limb & 81.1 & 207 & 263 & 261 & 22 & 35 & 44 \\
\hline Thoracic spine ${ }^{b}$ & 60.4 & 642 & 626 & 575 & 212 & 203 & 231 \\
\hline Sacroiliac joints ${ }^{b}$ & 55.7 & 693 & 729 & 691 & 218 & 260 & 298 \\
\hline Face $^{b}$ & 49.6 & 265 & 263 & 249 & 83 & 121 & 114 \\
\hline Cervical spine ${ }^{b}$ & 27.5 & 3513 & 3513 & 3362 & 1970 & 2224 & 2502 \\
\hline Head and MRA Brain ${ }^{b}$ & 18.1 & 171 & 187 & 181 & 96 & 132 & 144 \\
\hline Lumbar and sacral spine $e^{a b}$ & 17.4 & 7285 & 7620 & 7725 & 4589 & 5491 & 6401 \\
\hline Hip & 16.6 & 2034 & 2029 & 2028 & 1317 & 1429 & 1816 \\
\hline Total spine ${ }^{b}$ & 16.5 & 686 & 743 & 733 & 432 & 529 & 621 \\
\hline
\end{tabular}


Table 3 Average reduction (in \%) for period (P) 2 and 3 for examinations with more than 20\% reduction for period 2 including the average number of examinations for each period 2015-2019 as well as for 2020 (Continued)

\begin{tabular}{|c|c|c|c|c|c|c|c|}
\hline Examination & $\begin{array}{l}\text { Average reduction in } \\
\text { P2 and P3 (\%) }\end{array}$ & $\begin{array}{l}\text { Exam. in P1 } \\
\text { 2015-2019 }\end{array}$ & $\begin{array}{l}\text { Exam. in P2 } \\
2015-2019\end{array}$ & $\begin{array}{l}\text { Exam. in P3 } \\
2015-2019\end{array}$ & $\begin{array}{l}\text { Exam. } \\
\text { in } \mathrm{P} 1 \\
2020\end{array}$ & $\begin{array}{l}\text { Exam. } \\
\text { in P2 } \\
2020\end{array}$ & $\begin{array}{l}\text { Exam. } \\
\text { In P3 } \\
2020\end{array}$ \\
\hline$K_{n e e^{a b}}$ & 14.3 & 7433 & 7560 & 7707 & 5047 & 5713 & 6766 \\
\hline Calf & 13.3 & 362 & 363 & 387 & 282 & 287 & 336 \\
\hline Pelvis ${ }^{b}$ & 13.2 & 2301 & 2332 & 2283 & 1614 & 1752 & 2112 \\
\hline \multicolumn{8}{|l|}{ Ultrasound } \\
\hline Throat and neck ${ }^{\mathrm{b}}$ & 71.9 & 457 & 542 & 482 & 65 & 112 & 129 \\
\hline Liver, Gall Bladder, and Pancreas & 53.3 & 610 & 721 & 652 & 114 & 198 & 351 \\
\hline Axillar & 52.7 & 615 & 782 & 640 & 171 & 256 & 318 \\
\hline Pelvis & 45.4 & 109 & 104 & 106 & 28 & 45 & 60 \\
\hline Breast & 43.0 & 1795 & 1953 & 1812 & 723 & 905 & 1024 \\
\hline Abdomen and pelvis ${ }^{b}$ & 41.5 & 3540 & 3519 & 3331 & 813 & 1500 & 2165 \\
\hline $\begin{array}{l}\text { Fine needle aspiration cytology of } \\
\text { the breast }\end{array}$ & 40.0 & 482 & 505 & 502 & 222 & 271 & 277 \\
\hline Liver Ultrasound Elastography & 38.0 & 96 & 111 & 97 & 20 & 47 & 67 \\
\hline Abdominal aorta & 30.6 & 587 & 658 & 635 & 161 & 312 & 487 \\
\hline $\begin{array}{l}\text { Fine needle aspiration cytology of } \\
\text { thyroid }\end{array}$ & 29.0 & 198 & 186 & 210 & 80 & 113 & 148 \\
\hline Carotid arteries & 27.5 & 150 & 155 & 149 & 35 & 93 & 109 \\
\hline Scrotum & 27.5 & 1600 & 1620 & 1535 & 577 & 921 & 1212 \\
\hline Kidneys & 26.4 & 520 & 571 & 553 & 203 & 344 & 406 \\
\hline Thyroid $^{\mathrm{b}}$ & 26.0 & 838 & 869 & 848 & 187 & 450 & 712 \\
\hline Thigh & 25.1 & 109 & 122 & 106 & 30 & 59 & 97 \\
\hline Knee & 24.7 & 180 & 183 & 189 & 89 & 120 & 140 \\
\hline Urinary tract & 24.6 & 1304 & 1352 & 1257 & 429 & 771 & 1057 \\
\hline Liver & 22.4 & 505 & 536 & 534 & 161 & 307 & 451 \\
\hline Abdomen & 21.5 & 1947 & 1937 & 1803 & 790 & 1178 & 1613 \\
\hline Skin and subcutaneous & 20.7 & 341 & 316 & 311 & 107 & 194 & 284 \\
\hline Calf & 16.8 & 133 & 135 & 149 & 48 & 91 & 126 \\
\hline $\begin{array}{l}\text { Bladder ultrasound with Post-void re- } \\
\text { sidual volume measure }\end{array}$ & 16.7 & 142 & 140 & 140 & 66 & 73 & 146 \\
\hline Lower limb veins ${ }^{b}$ & 12.8 & 925 & 970 & 1013 & 536 & 731 & 886 \\
\hline
\end{tabular}

${ }^{\mathrm{a}}$ Codes related to the Choosing Wisely Campaign in Norway [28], ${ }^{\mathrm{b}}$ Codes related to the Choosing Wisely Campaign in the USA [5]

examinations are identified by the extended list of lowvalue radiology [5].

It is also important to notice that the burden of disease may be different during the studied periods as there were less activity during the close-down, e.g., fewer accidents. Moreover, population studies from Norway indicates that there were fewer strokes and infarctions during the start of the pandemic [52, 53].

The data describe the practical priority setting in radiology, which is interesting in itself. However, to use the data to identify candidates for low value care, we must assume that the practical priority setting roughly follows appropriateness criteria [4, 16] and the stated priority setting principles [54]. This means that the first outpatient examinations to start up and having the highest volume after the close-down would be those of higher value than those who stay low for longer. If not, that would mean that there was no systematic priority setting, e.g., due to high pressure on the services. However, the activity at the radiological departments has been low during lock-down and there are no indications of reduced radiological capacity due to illness among radiologists or radiographers after the lock-down period [55]. While there may be some local reticence of patients to attend imaging facilities for examinations during the first part of the epidemic, no changes in "no-show" rates are 
reported. Moreover, if patients had been scared from coming, they would most likely not show up for issues of less importance to them.

Additionally, radiological services were affected by the reduction in other outpatient services (referring patients to radiology) and in the number of elective surgeries. While this would reduce the number of examinations with explicit prioritization at the radiology department, the reduction may be due to overall priority setting.

In this paper, we provide a methodology to investigate changes to the health services during the pandemic to identify areas for further research. The bar of $50 \%$ change and 100 examinations per month is quite high. Many low-value services may be ignored by this approach, such as low-value low-volume interventional procedures. However, as there are fewer interventional procedures for the out-patient group than in the inpatient group, the loss may not be significant. Moreover, there may be many reasons for practice change, and we wanted to study the major changes.

There are also some limitations due to coding practices, which may vary. For example, there are codes for lower extremities and for foot and ankle. Furthermore, one code may be used for several clinical indications and could therefore represent both high and low value examinations. As pointed out, targeted investigation must be conducted to specify and mapping low value examinations. However, the objective of this study has not been to reveal variations or inconsistencies in coding practices, but only to study what is registered at face value and on a principal level.

Another limitation is the choice of study periods. Where to set the limits between periods is not given by nature. It is important to notice that the burden of disease may be different during the studied periods as there were less activity during the lock-down, e.g., fewer accidents, but also fewer strokes and infarctions during the start of the pandemic $[52,53]$. Adding additional study periods would provide more information on backlog and lasting effects.

However, the applied periods appear to be well chosen as the first period corresponds well with the close-down, the second with the opening somewhat, and the third with opening more [56]. This is also confirmed by reports by health authorities [51]. Figure 1 also indicates that there were very few covid-19 cases after Period 3. Moreover, the total reduction in Period 2 is $25.4 \%$ which corresponds well with other studies [29-34] and with the literature on overuse in radiological services $[5,57]$. It also indicates that our threshold is well selected.

The direct influence of the examinations of patients with SARS-COV-2 is expected to be very low as there were very few cases of SARS-COV-2 in Norway [58] and very few outpatient examinations related to SARS-COV-
2 as well as relatively few hospitalized patients with SARS-COV-2 that could influence the number of examinations of outpatients. However, there can be an indirect influence, e.g., cancelled elective outpatient treatments and surgery resulting in reduced pre/postoperative outpatient examinations and controls.

There are many ways to measure reduction. We have used percentage reduction compared to (the average of) the same period previous years, and to use Period 2 and 3 (and not Period 1) to identify potential low-value examinations. However, we noticed that examinations with the highest reduction rate for the various modalities are of relatively low volume examinations. Therefore, further research focusing on high volume examinations and examinations with potential high radiation dose would be welcome.

The results are specific for Norway and for outpatient radiological services. However, the results concur with other studies (on imaging and other services as referred above), and the identified examinations may be relevant for other countries, given the broad international collaboration and alignment. Moreover, this study presents a methodology to analyze the value of health services in other fields as well.

It is too early to verify that the identified examinations are of low value as the long-term effects of the reduction in 2020 are not assessable yet. Nonetheless, this study gives insights in practical priority setting and provides a specific set of potential low-value radiological examinations, and it presents a methodology for identifying them. The next step towards quality improvement is thorough analysis of the specific examinations, the corresponding clinical indications, and the assessment of the long-term effects of reduced services.

\section{Conclusion}

In this study, we propose and demonstrate a methodology using the SARS-COV-2 pandemic as a natural intervention to investigate practical priority setting in radiological services in Norway. We found a substantial reduction of the number of outpatient examinations, indicating how specific radiological examinations are valued in practice. As such, it can help us identifying potential low value radiological services. The imaging examinations with the most continuing reduction during the initial phases of the pandemic in 2020 was Abdominal KUB view, CT Enterography, MRI Pelvis and lower limb, Throat and neck ultrasound, MRI Thoracic spine, MRI sacroiliac joints, Liver, gall bladder and pancreatic ultrasound, Axillary ultrasound and MRI of the face. While the study confirmed a reduction in some examinations identified by the Norwegian and USA Choosing Wisely Campaign there was no clear pattern that indicated reduction in identified low-value examinations 
found in these guidelines. Further research should focus on in-depth analyses of examination codes, clinical indications, and long-term effects to verify specific radiological examinations as low value. Nonetheless, the SARS-COV-2 pandemic provides a natural intervention for identifying potential low value services and for quality improvement.

\section{Abbreviations}

DEXA: Bone density scan; KUB: Kidney, ureters and bladder; RSD: Relative Standard Deviation; RX: Conventional radiology; SD: Standard Deviation

\section{Acknowledgements}

We are most thankful to the Norwegian Health Economics Administration (HELFO) for providing data for the study.

\section{Authors' contributions}

$\mathrm{BH}$ designed the study. Data were acquired and analyzed by $\mathrm{BH}$ and $\mathrm{EK} . \mathrm{BH}$ made the first draft of the manuscript, which was critically revised in several rounds by EK and EA. All authors have approved of the final manuscript.

\section{Funding}

No funding bodies had any role in study design, data collection and analysis, decision to publish, or preparation of the manuscript. The research is funded by the Norwegian Research Council (IROS 302503).

\section{Availability of data and materials}

The datasets used and/or analysed during the current study available from the corresponding author on reasonable request.

\section{Declarations}

\section{Ethics approval and consent to participate}

Not applicable.

\section{Consent for publication}

Not applicable.

\section{Competing interests}

I certify that there is no actual or potential conflict of interest in relation to this manuscript, and there are no financial arrangements or arrangements with respect to the content of this comment with any companies or organizations.

Received: 28 April 2021 Accepted: 18 October 2021

Published online: 26 October 2021

\section{References}

1. Moynihan R, Johansson M, Maybee A, Lang E, Légaré F. Covid-19: an opportunity to reduce unnecessary healthcare. BMJ. 2020;370:m2752.

2. Pezeshki MZ, Janati A, Arab-Zozani M. Medical overuse in the Iranian healthcare system: a systematic scoping review and practical recommendations for decreasing medical overuse during unexpected COVID19 pandemic opportunity. Risk Manag Healthc Policy. 2020;13:1103-10.

3. Porter R. The greatest benefit to mankind: a medical history of humanity (the Norton history of science): WW Norton \& Company; 1999.

4. Sistrom CL. The ACR appropriateness criteria: translation to practice and research. J Ame Coll Radiol. 2005;2(1):61-7.

5. Levin DC, Rao VM. Reducing inappropriate use of diagnostic imaging through the choosing wisely initiative. J Am Coll Radiol. 2017;14(9):1245-52.

6. Fisher ES, Welch $\mathrm{HG}$. Avoiding the unintended consequences of growth in medical care: how might more be worse? JAMA. 1999;281(5):446-53.

7. Glasziou P, Moynihan R, Richards T, Godlee F. Too much medicine; too little care. BMJ. 2013;347:44247.

8. Brownlee S. Overtreated: why too much medicine is making us sicker and poorer: Bloomsbury; 2007.

9. Richards P. Too much medicine? BMJ. 1999:318(7178):268.

10. Moynihan R, Smith R. Too much medicine? BMJ. 2002;324(7342):859-60.
11. Moynihan R, Glasziou P, Woloshin S, Schwartz L, Santa J, Godlee F. Winding back the harms of too much medicine. BMJ. 2013:346:11271.

12. Papagiannis A. Too much medicine campaign is long overdue. BMJ. 2013; 346:f1723.

13. Pope T. Enough of too much. Appl Radiol. 2014;43(8):4

14. Bramson RT. Medical Utilization and Management. In: PACS: 2002: Springer; 2002. p. 395-414

15. Hofmann B. Too much of a good thing is wonderful? A conceptual analysis of excessive examinations and diagnostic futility in diagnostic radiology. Med Health Care Philos. 2010;13(2):139-48.

16. Powell DK, Silberzweig JE. The use of ACR appropriateness criteria: a survey of radiology residents and program directors. Clin Imaging. 2015;39(2):334-8.

17. Giancotti M, Rotundo G, Mauro M. Choosing wisely for health: a context analysis through a systematic search of the published literature; 2019.

18. Scott IA, Duckett SJ. In search of professional consensus in defining and reducing low-value care. Med J Aust. 2015;203(4):179-81.

19. Cohen E, Rodean J, Diong C, Hall M, Freedman SB, Aronson PL, et al. Lowvalue diagnostic imaging use in the pediatric emergency Department in the United States and Canada. JAMA Pediatr. 2019:173(8):e191439.

20. Hong AS. Low-value radiographic imaging apparently less employed in Canada vs US emergency departments. J Pediatr. 2019;214:238-41.

21. McGinn T, Cohen S, Khan S, Richardson S, Oppenheim M, Wang J. THE HIGH COST OF LOW VALUE CARE. Trans Am Clin Climatol Assoc. 2019;130:60-70.

22. Colla CH, Morden NE, Sequist TD, Schpero WL, Rosenthal MB. Choosing wisely: prevalence and correlates of low-value health care services in the United States. J Gen Intern Med. 2015;30(2):221-8.

23. Elshaug AG, McWilliams J, Landon BE. The value of low-value lists. JAMA. 2013;309.

24. Brady A, Brink J, Slavotinek J. Radiology and value-based health care. Jama. 2020;324(13):1286-7.

25. European Society of Radiology (ESR). ESR concept paper on value-based radiology. Insights Imaging. 2017:8:447-54.

26. Brady AP, Bello JA, Derchi LE, Fuchsjäger M, Goergen S, Krestin GP, et al. Radiology in the era of value-based healthcare: a multi-society expert statement from the ACR, CAR, ESR, IS3R, RANZCR, and RSNA. Insights Imaging. 2020;11(1):1-8

27. The Norwegian Directorate of eHealth. Prosedyrekodeverkene (Kodeverk for medisinske, kirurgiske og radiologiske prosedyrer, NCMP, NCSP og NCRP). Oslo: The Norwegian Directorate of eHealth; 2020

28. Gjør kloke valg - Radiologi [https://www.legeforeningen.no/foreningsledd/fa gmed/norsk-radiologisk-forening/artikler/fag-og-utdanningsstoff-fra-nora forum/gjor-kloke-valg-radiologi/].

29. Parikh KD, Ramaiya NH, Kikano EG, Tirumani SH, Pandya H, Stovicek B, et al. COVID-19 pandemic impact on decreased imaging utilization: a single institutional experience. Acad Radiol. 2020;27(9):1204-13.

30. Vagal A, Mahoney M, Anderson JL, Allen B, Hudepohl J, Chadalavada S, et al. Recover wisely from COVID-19: responsible resumption of nonurgent radiology services. Acad Radiol. 2020;27(10):1343-52.

31. Nyante SJ, Benefield TS, Kuzmiak CM, Earnhardt K, Pritchard M, Henderson LM. Population-level impact of coronavirus disease 2019 on breast cancer screening and diagnostic procedures. Cancer. 2021;127(12):2111-21.

32. Davenport MS, Fruscello T, Chatfield M, Weinstein S, Sensakovic WF, Larson DB. CT volumes from 2,398 radiology practices in the United States: a realtime Indicator of the effect of COVID-19 on routine care, January to September 2020. J Am Coll Radiol. 2021:18(3):380-7.

33. Sreedharan S, Mian M, McArdle DJT, Rhodes A. The impact of the COVID-19 pandemic on diagnostic imaging services in Australia. J Med Imaging Radiat Oncol. 2021. https://doi.org/10.1111/1754-9485.13291.

34. Naidich JJ, Boltyenkov A, Wang JJ, Cruzen E, Chusid J, Rula E, et al. Recovery of outpatient imaging utilization during the first wave of the COVID-19 pandemic. Clin Imaging. 2021;80:277-82.

35. Ohm E, Hauge LJ, Madsen C, Grøholt EK, Evensen M, Reneflot A. Impact of the COVID-19 pandemic on the treatment of injuries during lockdown in Norway. Scand J Public Health. 2021:49(7):689-96.

36. Lacson R, Shi J, Kapoor N, Eappen S, Boland GW, Khorasani R. Exacerbation of inequities in use of diagnostic radiology during the early stages of reopening after COVID-19. J Am Coll Radiol. 2021;18(5):696-703.

37. Cavallo JJ, Forman HP. The economic impact of the COVID-19 pandemic on radiology practices. Radiology. 2020;296(3):E141-4.

38. Alvin M, George E, Deng F, Warhadpande S, Lee S. The impact of COVID-19 on radiology trainees. Radiology. 2020;296(2):246-8. 
39. Moynihan R, Sanders S, Michaleff ZA, Scott AM, Clark J, To EJ, et al. Impact of COVID-19 pandemic on utilisation of healthcare services: a systematic review. BMJ Open. 2021;11(3):e045343.

40. Sorenson C, Japinga M, Crook H, McClellan M. Building a better health care system Post-Covid-19: steps for reducing low-value and Wasteful care. NEJM Catalyst Innovations Care Delivery. 2020;1 (4):1-10. https://doi.org/10.1056/ CAT.20.0368

41. Sorenson C. Running the numbers: capitalize on the moment: leveraging the COVID-19 experience to spur low-value care reduction in North Carolina: a periodic feature to inform North Carolina health care professionals about current topics in health statistics. N C Med J. 2021;82(4): 294-8.

42. Kim DD, Ollendorf DA, Neumann PJ, Fendrick AM. Crisis into opportunity: can COVID-19 help set a path to improved health care efficiency? Am J Manag Care. 2020;26(9):369-70

43. Auener S, Kroon D, Wackers E, Van Dulmen S, Jeurissen P. COVID-19: a window of opportunity for positive healthcare reforms. Int J Health Policy Manag. 2020;9(10):419.

44. Oakes AH, Segal JB. The COVID-19 pandemic can help us understand lowvalue health care. Health Aff. 2020;27. https://doi.org/10.1377/hblog20201 023.522078 .

45. Basharat S, Born K. Using Health Care Resources Wisely After the COVID-19 Pandemic: Recommendations to Reduce Low-Value Care. Can J Health Technol. 2021;1(5):1-29. https://doi.org/10.51731/cjht.2021.71.

46. Moynihan R, Johansson M, Maybee A, Lang E, Légaré F. Covid-19: an opportunity to reduce unnecessary healthcare. British Med J Publishing Group. 2020;370:m2752. https://doi.org/10.1136/bmj.m2752.

47. Roth $A R$, Lazris $\mathrm{A}$. Benefits of avoiding unnecessary medical care during the COVID-19 pandemic. Am Fam Physician. 2021;103(10):584-5.

48. Abrams EM, Singer AG, Shaker M, Greenhawt M. What the COVID-19 pandemic can teach us about resource stewardship and quality in health care. J Allergy Clin Immunol Pract. 2021;9(2):608-12.

49. Pendrith C, Bhatia M, Ivers NM, Mecredy G, Tu K, Hawker GA, et al. Frequency of and variation in low-value care in primary care: a retrospective cohort study. CMAJ open. 2017;5(1):E45.

50. Helsedirektoratet. Endringer i aktivitet i helsetjenester mars og april 2020 Oslo: Directorate of Health. p. 2020

51. Commission E. Medical radiation exposure of the European population. In: Radiation protection report № 180. Brussels: European Commission; 2014. p. $1-181$.

52. Myhre PL, Grundvold I, Paulsen TH, Omland T, Schirmer H. Cardiovascular hospitalizations, influenza activity, and COVID-19 measures. Circulation. 2020; 142(13):1302-4.

53. Kristoffersen ES, Jahr SH, Thommessen B, Rønning OM. Effect of COVID-19 pandemic on stroke admission rates in a Norwegian population. Acta Neurol Scand. 2020;142(6):632-6.

54. Hofmann B. Priority setting in health care: trends and models from Scandinavian experiences. Med Health Care Philos. 2013;16(3):349-56.

55. Molvik M, Danielsen AS, Grøsland M, Telle KE, Kacelnik O, Eriksen-Volle H-M. SARS-CoV-2 blant ansatte i helse- og omsorgstjenesten. Tidsskr Nor Laegeforen. 2021;141:1-11. https://doi.org/10.4045/tidsskr.20.1048.

56. Whittaker R, Grøsland M, Buanes EA, Beitland S, Bryhn B, Helgeland J, et al. Sykehusinnleggelser med covid-19-en sammenligning av ulike datakilder. Tidsskr Nor Legeforen. 2020;(Online).

57. Rao VM, Levin DC. The overuse of diagnostic imaging and the choosing wisely initiative. Ann Intern Med. 2012;157(8):574-6.

58. Telle KE, Grøsland M, Helgeland J, Håberg SE. Factors associated with hospitalization, invasive mechanical ventilation treatment and death among all confirmed COVID-19 cases in Norway: prospective cohort study. Scand J Public Health. 2021:49(1):41-7.

\section{Publisher's Note}

Springer Nature remains neutral with regard to jurisdictional claims in published maps and institutional affiliations.

Ready to submit your research? Choose BMC and benefit from:

- fast, convenient online submission

- thorough peer review by experienced researchers in your field

- rapid publication on acceptance

- support for research data, including large and complex data types

- gold Open Access which fosters wider collaboration and increased citations

- maximum visibility for your research: over $100 \mathrm{M}$ website views per year

At BMC, research is always in progress.

Learn more biomedcentral.com/submissions 